\begin{tabular}{|c|c|}
\hline & $\begin{array}{l}\text { International Journal of Trend in Scientific } \\
\text { Research and Development (IJTSRD) }\end{array}$ \\
\hline 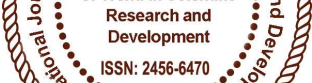 & International Open Access Journal \\
\hline 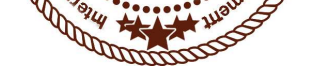 & ISSN No: 2456 - 6470 | www.ijtsrd.com | Volume - 2 | Issue - 2 \\
\hline
\end{tabular}

\title{
Social Media and Political Communication in India: An analysis of 2017 Legislative Assembly Elections in Himachal Pradesh
}

\author{
Ashish Sharma \\ Asst. Professor-II, Amity School of \\ Mass Communication, Amity University, Gwalior
}

\section{ABSTRACT}

Politics and Mass Communication have been an unbreakable duo for many centuries. Public meetings, Newspapers, Magazines, Radio, Television are the major communication tools. With the advent of new media technologies, the political campaign has gained a new dimension. During the last elections Indian political parties used Websites, E-mails, IVRS, SMSs, Internet, Banners, Online Advertising, Blogs, Mobile Phones, etc. This study has aimed to assess the effectiveness of new media political campaigns during the elections. Content analysis, Survey and In-depth Interview methods were used in the study. The study has revealed surprising facts. Every large political party has tried to use all the available new media tools. Television, Mobile phone and Internet have played a great role. The utilization of new media communication tools and strategies gave a new facet that was highly beneficial to the Indian politics. The political parties have reached a large number of voters through the new media. It made their election campaign easy, fast and successful. This paper aims to examine the extent use of social media by the political parties to promote their image and political messages, among their supporters and peoples in social media. The paper intends to examine how people consume the political issues or political discussion on social media. It was studied on the basis of the responses received from a sample of 100 respondents in Shimla, Himachal Pradesh. Results reveal interesting information on the types of social media used the ratings of the most used social media and their impact on society.

Keywords: Social Media, Political Communication, Elections, Campaign Strategies

\section{Introduction}

Social Media and its tools has made it convenient for us to stay abreast with all that is happening in the society and more importantly, to be able to react to it. With the use of devices like laptop, smart phones, tablets and the like, we are not only making use of the new media, but doing it very efficiently and up-to-themark. Social network sites, weblogs, applications, software, emails, allow us to communicate and put new media to the best possible use.

These have become major tools for people to stay connected with friends and families and share their lives through pictures or words. People also utilize social network sites to stay updated vis-à-vis happenings in the society. And modes of new media have become a Zen for a number of people irrespective of their age. It is a medium that draws attention and people have started considering it a pivotal part of their lives, and for a lot of them their daily lives are almost connected rather governed by social media, of any sort. New media has also been understood as a significant medium to understand the practices, norms, implications, cultural diversity of people hailing from different backgrounds. It can create a clearer, enhanced comprehension among cultures, enhance the levels of tolerance of people, and bring communities together. Hereby, New Media sites aren't just a medium to connect people; they rather connect social sects, and can bring about 
significant positive changes in the social setup too. After all, these are media of communication, and if used aptly they can get the right message across to the right audiences, thus helping in escalating people's social life index, also termed as satisfaction with life index (White, Adrian, 2007).

To begin with, there is a need to understand the term New Media in general, and in the context of the present study.

\section{Political Communication}

New Media Institute's Bailey Socha and Barbara Eber-Schmid define New Media as "a $21^{\text {st }}$ Century catchall term used to define all that is related to the internet and the interplay between technology, images and sound." It is to be noted that the definition of new media will not be consistent over time and will see a change on almost an everyday basis. To predict the character of new media for even a near future is a cumbersome task, so to say, due to its ever-evolving nature. However, to get a perspective, one needs a base-line to understand new media as a concept, even if it keeps changing constantly and is ever-growing. Hence, we hereby stick to how Wikipedia defines new media, which is- "A broad term in media studies that emerged in the latter part of the $20^{\text {th }}$ century. For example, new media holds out a possibility of ondemand access to content anytime, anywhere, on any digital device, as well as interactive user feedback, creative participation and community formation around the media content. Another important promise of new media is the 'democratization' of the creation, publishing, distribution and consumption of media content. What distinguishes new media from traditional media is the digitizing of content into bits. There is also a dynamic aspect of content production which can be done in real time, but these offerings lack standards and have yet to gain traction."

Socha and Eber-Schmid in their paper also mention that it is to be understood that "Wikipedia is an example of combining Internet accessible digital text, images and video with web-links, creative participation of contributors, interactive feedback of users and formation of a participant community of editors and donors for the benefit of non-community readers. Facebook is an example of the social media model, in which most users are also participants."

\section{Social and Political Communication}

The use of social media for political agendas in India is a new concept. However, the rise in the use of social media in political campaigns in India cannot be overlooked now. India's main political parties - 'The Indian National Congress' and 'The Bhartiya Janta Party' are tapping into the social media platforms like Face book and Twitter. They are doing so to outinnovate each other.

There are two main important drivers that have led to the adaptation of social media by political parties in India.

- To reach out to millions of potential voters who otherwise are difficult to meet in person.

- To tap into 90+ million Face book users who are expected to influence election results in year 2014 . This year alone there are over 100 million first time registered voters in the country.

Political information exchanges have been driven not by the government but by third parties, which is mostly the citizens and the foundations or non-profits organizations looking for encouraging the increased participation of young generation in Indian politics. Therefore, social media used in politics is bringing together the public through its rapid and two-way interaction.

The Internet and social media usage is certainly an evolving force in Indian politics, this gives rise to a key question: whether this rise is good for Indian politics or not. While discussing the effect of the Internet on politics, Nelson (2010) argues that the Internet's power to disseminate information has created an environment in which any individual can possibly find and motivate like-minded people to take political actions. Additionally, just how effective the use of social media can be on the electoral front in India was displayed when the Aam Aadmi Party (AAP) Party won and got elected in power for Delhi in December 2013. As many people have ability to influence their families, that's what happened here, when kids who were active on social media asked their parents to vote in favor of AAP part instead of congress after reading facts on social media. Moreover, the report released by the Internet and Mobile Association of India and IRIS Knowledge Foundation stated that of India's 543 constituencies, 160 could be called as high impact in the forthcoming elections for year 2014 . 
Social media in the next general elections will most likely influence these high impact constituencies where the Face book users account for over $10 \%$ of the registered voting population (Indexoncensorship.org, 2014). Since independence for many years, election campaigns in India were designed around public rallies, public welfare schemes, and public related events or in the form of television or radio advertisements.

Therefore, with political discussion now taking place on social media sites such as Face book and twitter give rise to a relevant question:

- Could activities on these sites be a predictor of election results and prove to be an actual game changer by influencing voters in India?

- Whether the use of these sites as a platform for political deliberations effective? And if so, to what extent can it be influencing in changing the decisions of the Indian registered voters.

During 2014's Indian lok sabha general elections, the political leader Mr. Narendra Modi made use of social media to a great extent as compared to the opposition leader Mr. Rahul Gandhi. Many people are attributing the win of Mr. Narendra Modi to adaptation of technology of social media. For instance, the victory message by Mr. Narendra Modi was the highest retweeted message on twitter in Indian history. Another example of use of Social media in politics was in 2014 Delhi election when AAP came into power by seeking donation and votes over the social media. They not only receive the funding but also managed to attract a large number of activists to promote their election campaign. A large part of the credit of electoral victories of Mr. Naveen Patnaik, Chief Minister of Orissa, goes to his social media campaign. Mr. Nitish Kumar, Chief Minister of Bihar hired the same team that Mr. Narendra Modi used in 2014 to carry out his social media campaign during Lok Sabha elections. Thus in last five years, we can say social media has become an important factor in deciding the fate of various political parties.

PM. Modi along with Dr. Shashi Tharoor was among the few Indian politicians to have their accounts on various social platforms like Facebook, Twitter and Google +. AAP used pin storm to compare how the party is faring against other parties. Political parties followers fought \# hashtag wars on social media platforms.AAP used twitter for $3 / 4$ of their social media connections. Today politicians are organizing
Google + Hangouts to reach out voters. Market Pundits expected that next general elections in 2019 to be dependently largely on the social media presence of political parties in India and the brands they creates for themselves.

\section{Literature Review}

In present century as we know Social media is a highly influential and powerful medium of communication. With the advent of social applications like Social Networking Sites (SNS) i.e. Face book, LinkedIn, Microblogging services like Twitter, Photo and Video sharing services like Instagram, YouTube, Photo-bucket / Flickr now million of people exchanges their ideas, thoughts in different forms such as posts, tweets, images, videos ,GIF .Social media is one of the best way to interact with the people. Today social media also plays a prominent role in Political activism in different ways.

Social Media has changed the structure and roots of contemporary political communication (Tenhunen \& Karvelyte, 2014). Social media provides platform to the politicians and political parties to interact, share and exchange information with their voters/ citizens (audience). These social networking sites (SNS) are upgrading the methods and structures of political communication from traditional to digital and also providing a platform for the political parties and citizens to engage themselves in the activities related to the politics. Politician's engagement level in the social media during election and election campaign also helps to predict the voting behavior of audience. Politicians try to influence audience/ citizens by the use of political communication in socials media.

In his study Narasimhamurthy (2014) found the political parties' use of social media as a tool for political communication during the 2014 election campaign. The researcher examined social media's reach over individual voters in India. The 'gratification' approach was used to analyze face book, twitter, social blogs, search engines and micro blogs. The study found that most social media users enjoy the highest levels of online connectivity and believe that information coming through social networking sites to be reliable. In the 2014 elections, political par-ties and candidates used social media heavily to engage with voters, recruit campaign volunteers and raise campaign funds. This election campaign brought to the limelight, the importance of social networking sites for political parties for 
communication. This election also witnessed the effects, use and adoption of social media.

Malik (2014) studied the social media impact on individual voters in India. The involvement of Social media in Indian politics and political campaigning is found in full strength, yet it has a smaller impact on individual-voter behavior that comes from huge offline political influence from a politician or his party. Updates regarding political leaders are sought by the active users only.

Methi (2014) states that Political communication methods used in today's digital age, gives a chance to both political parties and voters to interact with one another. Thus, political activities may gain more transparency, giving citizens a chance to engage in political decision-making processes. Political parties reap the benefits of enhancing their image and political messages using social networking sites and enjoy the active participation of their supporters on Face book.

\section{Vinay, Kumar and Hosurmath's (2014) study} attempts to study how social media affects Indian politics. Social media users between the age group of $15-45$ are considered in this study. The authors found that frequency of updates and 'con-tent relevancy' determined the perception of value. They found that unlike US, the Indian politics is yet to reach the point where social media can completely swing elections. The truth is that social media is definitely reaching a point where its influence is growing and getting stronger by the day.

Anderson (2015) examined India's gender digital gap in relation to women and politics on twitter. This study tries to conceptualize if women are marginalized and less-involved in political conversations that happen online in India. Analysis of 23,350 tweets over eighty day's period shows an overwhelming under-representation of women in Twitter's political discussions that mirror the realworld women's marginalization in political process in our country.

Michael Gurevitch, Stephen Coleman and Jay G. Blumler in their essay 'Political Communication Old and New Media Relationships' discuss how there has been a paradigm shift in the way the relationship between politicians and media has evolved. The television-politics relationship though continues to be strong in terms of ownership pattern and appointment of key positions in media houses, digital media is giving a tough competition to this model of political communication. Political communication has established a strong relationship through Twitter. Twitter began as a social media platform but today it plays a crucial role as influencer to bring about a social change or even a revolution like Arab Spring an Egyptian revolution and other such uprisings. Since twitter became a part of social history through the many revolutions, it has aided this information gained from masses to achieve confirmation on what media can do to provide detailed evidences about how technology-based social networks form and evolve over a period of time. According to Margot Gerritson, Head of Stanford University, Center of Excellence for Historical Significance, 'I think Twitter will be one of the most informative resources available economic, social, and political trends, as well as consumer behavior and social trends' (American Libraries, 2010).

\section{Social media and its uses within Indian Political} Scenario

Social media is playing a considerable new role in Indian democracy. With the changing politics of India political parties and politicians have found a new ways of reaching out to a younger and aspiration population.

The use of social media by Indians was first highlighted during the 2008 Mumbai attacks when information shared through Twitter and Flickr between Indians and the outside "The second mass use of social media in India was the May 2009 national elections, when, for the first time, online voter registration and transparency campaigns started" where first time political parties tried to reach out to voters through social networking websites.

However, all of these are still in trend, but increasingly in urban India, political parties are becoming tech savvy as this is the only way to reach out eloquent youths. Among major political parties in India, BJP has the biggest charisma in social media. BJP started using the social media even before 2009 general election, which it lost. But in recent years, it has dig deeper into social media. Several senior leaders like Sushma Swaraj, Rajnath Singh, Arun Jaitley, Narendra Modi and many are on social networking sites. Narendra Modi as the BJP's prime 
ministerial candidate for the 2014 general election has his own team for his social media management.

Social media has also credited with helping the new Aam Aadmi Party and its candidate, Arvind Kejriwal, won a surprise victory in Delhi against major political parties. But social media can also be subject to significant abuse. Some politicians have been accused of boosting their apparent popularity on social media with legions of followers who don't exist and of using social media to smear their opponents. Worse, social media have been used to fan violence against religious and ethnic groups.

Functions of social media as a new tool in Indian general election

In the context of relationship between politicians, social media and public, identifies number of functions that Internet have as follows:

- Politicians promote their controlled speech and present their point of view without being interrupted by journalists or by media format limitation.

- Social media has given privilege for politicians to post a presumptive political agenda.

- By means of social media, political parties or politicians can mobilize public and invites them to participate in discussion on some issues of public interest.

- By using the social media tools, politicians and political parties interacts apparently with more efficiently with their supporters, beyond institutional and bureaucratic rigors.

\section{Objectives of Study}

The major objective of the present study is to understand the intervention of social media in Himachal Pradesh Legislative assembly elections 2017. The specific objectives of the present study are as follows:

- To identify the various social media platforms used by the respondents.

- To understand the popularity of social media platforms.

- To identity the popular social media platform used by respondents for political awareness.

- To study the impact of social media on society.

\section{Methodology}

Survey method will help to collect data from each sample. According to Kraemer Survey research quantitatively is use to describe certain aspects of a given population. These aspects typically include the examination of the relationship between variables. Second, survey data needed for research, therefore, are relative gathered from people. Finally the research results of the survey can be returned to the general population from which a selected portion of the population uses.

Survey method is selected as it is well planned. It can be generalized and can be statistically analysed. To meet the requirement of the study Two-way stratification sampling was adopted for data collection from the target population.

The scope of the study comes under the Shimla city in Himachal Pradesh region. Questionnaire method has been followed to collect the data from users of the study in which 120 questionnaires were distributed and then total 100 respondents equally consisting 50 male and 50 female respondents were selected randomly from them.

Table 1 shows that 50 are male respondents and 50 are female respondents covered in the study.

\begin{tabular}{|l|l|l|}
\hline Sex & Respondents & Percentage \\
\hline Male & 50 & 50.0 \\
\hline Female & 50 & 50.0 \\
\hline Total & 100 & 100.0 \\
\hline
\end{tabular}

Table 1: Gender of the Respondents

In Table 2 we have shown the age of respondents in which majority of the respondents 41.0 per cent covered are in the age group between 26 to 40 years of age, 37.0 per cent of respondents are under the age category 18 to 25 years of age and the rest 22.0 per cent belongs to age group of $40-55$ years

\begin{tabular}{|l|l|l|}
\hline Age & Respondents & Percentage \\
\hline $18-25$ & 37 & 37.0 \\
\hline $26-40$ & 41 & 41.0 \\
\hline $40-55$ & 22 & 22.0 \\
\hline Total & 100 & 100.0 \\
\hline
\end{tabular}

Table 2: Age of the Respondents.

Table 3 clearly shows the maximum numbers of respondents are of social media sites such as Facebook, Twitter, Whatapp, LinkedIn and many more. While, the least 3 per-cent of respondents are unaware of social media platforms 
International Journal of Trend in Scientific Research and Development (IJTSRD) ISSN: 2456-6470

\begin{tabular}{|l|l|l|}
\hline Awareness & Respondents & Percentage \\
\hline Yes & 97 & 97.0 \\
\hline No & 3 & 3.0 \\
\hline Total & 100 & 100.0 \\
\hline
\end{tabular}

Table 3: Awareness on Social Media Sites.

Table 4 clearly shows that less than half of the respondents found to use social media between two and three hours (35 per cent). 20.0 per cent prefer using less than two hours, 25.0 per cent for 3-4 hours and 20.0 per cent members prefer for more than 4 hours per day.

\begin{tabular}{|l|l|l|}
\hline $\begin{array}{l}\text { Hours spent } \\
\text { per day }\end{array}$ & Respondents & Percentage \\
\hline$>2$ Hour & 20 & 20.0 \\
\hline 2-3 Hour & 35 & 35.0 \\
\hline 3-4 hour & 25 & 25.0 \\
\hline$<4$ Hour & 20 & 20.0 \\
\hline Total & 100 & 100.0 \\
\hline
\end{tabular}

Table 4: Time Spent on Social Media Sites.

In term of popularity among social media Table 5 clearly shows that Face book is the most popular social networking sites among respondents $(5$ per cent) than other SNS followed by Whatsapp (22 per cent), Twitter (11.0 per cent), LinkedIn ( 7 per cent) and Google Plus 5 per cent, while the least LinkedIn is used by only 4 per cent of respondents

\begin{tabular}{|l|l|l|}
\hline SNS & Respondents & Percentage \\
\hline Facebook & 55 & 55.0 \\
\hline Whatsapp & 22 & 22.0 \\
\hline Twitter & 11 & 11.0 \\
\hline Google Plus & 5 & 5.0 \\
\hline Linkedin & 7 & 7.0 \\
\hline Total & 100 & 100.0 \\
\hline
\end{tabular}

In cases of using social media Table 6 clearly shows that entertainment is the main purpose behind using social media among respondents.

\begin{tabular}{|l|l|l|}
\hline Purpose & Yes & No \\
\hline Entertainment & 65 & 35 \\
\hline Creating Groups & 45 & 55 \\
\hline News & 48 & 52 \\
\hline Employment & 24 & 76 \\
\hline $\begin{array}{l}\text { Sharing Files and } \\
\text { Information with } \\
\text { Friends/ family }\end{array}$ & 60 & 40 \\
\hline $\begin{array}{l}\text { Making New } \\
\text { Friends }\end{array}$ & 28 & 52 \\
\hline Others & 25 & 75 \\
\hline
\end{tabular}

Table 6: Purpose of using Social Media Sites

Table 7, majority of respondents 38 per cent prefer the micro-blogging site, Twitter, for political information as most of the Indian politicians tweets their latest political updates. Followed by 30 per cent prefer Facebook, 20 per cent on Whatsapp, 7 per cent for Google Plus while only 5 per cent prefer LinkedIn.

\begin{tabular}{|l|l|l|}
\hline Preferences & Respondents & Percents \\
\hline Facebook & 30 & 30.0 \\
\hline Whatsapp & 20 & 20.0 \\
\hline Twitter & 38 & 38.0 \\
\hline Google Plus & 7 & 7.0 \\
\hline Linkedin & 5 & 5.0 \\
\hline Total & 100 & 100.0 \\
\hline
\end{tabular}

Table 7: Preferences of getting political information by using Social Media Sites

Table 8 clearly shows that in term of engagement (Like + Share + Comment) on social media Chief Minister Sh. Virbhadra Singh will be the most prominent and famous leaders in Himachal Pradesh.

\begin{tabular}{|l|l|l|l|l|}
\hline Political Leader & Party Affiliation & Yes & No & Total \\
\hline Virbhadra Singh & INC & 75 & 25 & 100 \\
\hline $\begin{array}{l}\text { Prof. Prem Kumar } \\
\text { Dhumal }\end{array}$ & BJP & 60 & 40 & 100 \\
\hline Vikrmaditya Singh & INC & 55 & 45 & 100 \\
\hline Rakesh Singha & CPI M & 45 & 55 & 100 \\
\hline Jairam Thakur & BJP & 40 & 60 & 100 \\
\hline
\end{tabular}

Table 8: Popular political figure on social media sites 
The purpose of this study is to understand to what extent social media use for political activities influences political efficacy, political knowledge, and political participation among peoples in Shimla, Himachal Pradesh region.

The results show that the use of social media for political activities influences peoples' political efficacy, political knowledge, and political participation. The study also shows that social media users may discover political activities in social media and by this way intensify their political knowledge, increase their political efficacy, and improve their political participation. Moreover, the social media usage for political activities was influenced by frequency of general social media use. The more often they use social media, the more often they use social media for political activities.

The study shows that, for those who discussed the election on social media, the role of the web in this regard is significantly stronger than that of the mass media. Twitter attracts a very peculiar subset of citizens, who differ from the population writ large in terms of demographic characteristics. Engaging with politics through the web is conducive to greater faceto-face involvement and the propagation of digitally acquired information through interpersonal interaction, and these effects seem to occur regardless of the individual's social and demographic characteristics. The findings suggest the possibility that as more begin to use social media to discuss politics; we will begin to see even more offline discussion of politics.

The results suggest that what happens online does not stay online, but rather moves offline and affects citizens' face-to-face conversations. To the extent that this is true, the political demands that are articulated through social media will become harder to ignore for anyone who is interested or involved in the political process, including those who are inclined to study it.

\section{References}

1. Dutta S, Fraser M (2008) Barack obama and the Facebook election. U.S. News \& World Report.

2. Akar E (2011) An examination of the factors influencing consumers attitudes toward social media marketing. Journal of Internet Commerce 10: 35-67.

3. Antonio M (2013) Social Media- PR Tools for Romanian Politicians? Procedia - Social and Behavioral Sciences 81: 116-121.

4. Open Source Centre (2010) OSC Media Aid: Overview of Leading Indian Social Media.

5. Stoffer T (2014) The Use and Impact of Social Media in Political Elections. University of Maryland, College Park.

6. https://en.wikipedia.org/wiki/Social_media

7. Meti V, Khandoba PK, Guru MC (2015) Social Media for Political Mobilization in India: A Study. J Mass Communicat Journalism 5:275. doi:10.4172/2165-7912.1000275

8. Darshan, B. M., \& Suresh, K. Changing Structures of Contemporary Political Communication: A Review of Literature Related to Social Networking Sites in the Indian Political Context.

9. Gurevitch, M., Coleman, S., \& Blumler, J. G. (2009). Political communication-Old and new media relationships. The ANNALS of the American Academy of Political and Social Science, 625(1), 164-181 